\title{
Gender \\ Mainstreaming: Failings in implementation
}

can only be as good as its implementation. Focus on the critical move from policy to institutional practice raises important concerns, including the risk that strategies lose their ideological substance in implementation processes. This is a particular concern with strategies requiring transformative approaches, such as gender mainstreaming. 'Policy evaporation' refers to the fact that policies may remain 'words on paper' with no real impact. The UN Commission on the Status of Women regretted the gap between policy and practice in its 2005 review of national implementation of the Platform for Action and called for accelerated implementation efforts (UN 2005). Users with different agendas can have significant impact on implementation. Those unaware of the underlying transformative nature of strategies may undermine full potential through poor application. Strategies can also be deliberately 'misused' for purposes at odds with original intentions. The greatest 
challenge facing mainstreaming today is inadequate implementation. Gender mainstreaming has never been fully achieved. The strategy has never, in any context, received the investment required for success. Even where organizations have made considerable efforts, the approach has not been as transformative as intended. It is therefore somewhat premature to talk about the failure of the strategy; what needs to be discussed is instead a serious failure in implementation.

Gender mainstreaming has faced significant implementation challenges. The strategy has been highjacked by actors falsely claiming that it requires removal of specific attention/resources for gender equality, with references to mainstreaming used as an excuse for dismantling existing mechanisms/funds or discouraging new initiatives. There have been claims that mainstreaming depoliticizes gender equality; is not sufficiently transformative; and has proven unsuccessful in promoting gender equality. Calls for its replacement have come from different sources but none rejecting mainstreaming have presented viable alternatives. Interestingly these complaints have not come from states but from academics, researchers and disaffected practitioners, including in donor agencies, NGOs and the UN. Since endorsing the strategy in 1995, UN Members have adopted further recommendations to enhance implementation.

Implementation of gender mainstreaming remains critical for achievement of gender equality. Mainstreaming provides a unique opportunity to influence policy agendas, including through impact on data collection, analyses, policies, strategies and resource allocations which are important for gender equality. Mainstreaming should, therefore, be at the core of gender equality efforts of the UN and states. The UN has played a key role in promoting, supporting and monitoring implementation. In 1997, the Economic and Social Council provided a working definition and strategic guidelines which continue to guide work (UN 1997). Initially, strong leadership on implementation was provided by UN headquarters. In recent years, this leadership has become diffuse and weak. Although a system-wide policy exists (UN 2006), entities are largely left to their own resources. Many individual entities have, however, shown significant leadership in their areas of responsibility.

Furthering implementation will require increased understanding of the strategy, including through attention to persistent misperceptions. Most basic is the understanding that mainstreaming is a strategy, not a goal. It is not an end in itself but a means towards the goal of gender equality. Mainstreaming must always be linked to the achievement of equality. Equally important is highlighting that implementation not only promotes gender equality but also contributes to effective achievement of sector goals. Not taking into account the priorities, needs and contributions of both women and men seriously compromises the potential for success of interventions in any policy area. Where policies and programmes are based on gender analyses, and involve both women and men as stakeholders, potential is significantly increased.

Mainstreaming was developed to move beyond unquestioningly integrating women into policies and programmes to systematically identifying transformation needed to make processes sufficiently gender-responsive and ensure that women and men participate, influence and directly benefit. It requires attention to gender equality from initial stages to ensure greatest impact on outcomes.

A common false perception is that mainstreaming leads to the exclusion of other strategies for gender equality, including those specifically targeting women's priorities and needs. The Beijing Platform for Action makes clear that mainstreaming is one strategy and calls for a 'dual approach' using both mainstreaming and targeted in- 
terventions (UN 1996). The misperception of mainstreaming as a western imposition negates the importance of debates/discussions on the strategy, involving countries large and small from all regions, prior to its endorsement in the Platform for Action. Claims that mainstreaming imposes a 'blanket' solution disregarding regional and national-level differences are similarly misguided. Implementation of mainstreaming should always be context-specific, while keeping within established global goals and principles and in particular not undermining human rights. Claims about de-politicizing effects of mainstreaming include an unquestioning adaptation to existing conservative agendas. This claim simply illustrates the fact that mainstreaming has not been implemented in a transformative manner. The mainstreaming process should transform policy agendas rather than adapt to them.

A particularly persistent misperception is that mainstreaming is about achieving gender balance in staffing. Although the goal of gender balance is certainly essential for gender equality, it is not the purpose of mainstreaming. Mainstreaming aims to ensure attention to gender equality in substantive work. While this can be facilitated by equal involvement of women and men in the work of an organization, it cannot be automatically presumed that all women are gender-sensitive and committed to gender mainstreaming. Equating mainstreaming with women's participation is a related misinterpretation. Mainstreaming goes beyond ensuring participation as actors and beneficiaries - although this is an essential element. By limiting its scope, these two misperceptions depoliticize the strategy and deny its potential impact on substantive work. Successful mainstreaming is not simply a technical issue as sometimes suggested; implementation goes beyond technical inputs such as training, methodologies and tools. There is an important political context, requiring commitment and visible leadership, adequate resources, and accountability mechanisms (Hannan 2008).

Accelerating implementation could be facilitated by utilizing lessons learned from UN mainstreaming efforts. Almost all UN entities have made achievements in making gender mainstreaming part of equality policies, establishing specialist staff and developing specific methodologies and tools and training. Many entities also report significant efforts to mainstream gender perspectives at programme level.

Serious gaps and constraints have, however, also been identified. One of the most persistent problems is the continued separateness of gender equality efforts. While most organizations have gender equality policies, not enough has been done to ensure gender equality is systematically incorporated as a goal into overall organizational policies and sector policies and strategies. This creates a serious gap in organizational mandates and rationales for mainstreaming and results in continued perceptions of gender equality as separate rather than an integral part of work across all sectors. The problem of separateness can be illustrated by inadequacies in methodology development. Although useful mainstreaming methodologies and tools have been created, gender perspectives are not necessarily incorporated into sector methodologies and tools. While gender analysis may be undertaken as separate analysis, gender perspectives are not systematically considered in other pertinent analyses - for example, on human rights, poverty and environmental impact. While excellent gender mainstreaming evaluations have been carried out, gender mainstreaming is not always a part of other important evaluations (Hannan 2008).

The most serious constraint to full implementation within UN organizations is the lack of visible leadership from top and middle-level management, as well as resulting failures to establish effective accountability mechanisms. Policies with top-level 
endorsement in organizations can be undermined by lack of engagement at middle management level. Even where gender equality policies are in place, action is not always mandatory - there is no accountability and no sanctions for non-compliance. Despite training programmes, capacity is under-developed in many organizations. The full potential of capacity-building is not harnessed when training programmes are not tailored specifically to needs of staff. Methodologies and tools developed to guide staff may be unnecessarily complex, which detracts from their systematic use (Hannan 2008).

Improving implementation of gender mainstreaming requires the development of a well-resourced implementation plan which specifically addresses identified gaps and constraints. Developing effective accountability mechanisms, and increasing monitoring and reporting on progress, is a critical and difficult area. Recent innovations such as score-cards and gender audits can facilitate implementation if sufficient attention is given to inspiration and motivation and incentives. Positive change on gender mainstreaming requires commitment of staff rather than unwilling compliance. Disseminating promising practices is more effective than cataloguing poor practice.

While implementation of gender mainstreaming at country level remains the responsibility of States, the UN has a key role in providing leadership and support-in- cluding by offering a positive role model and through monitoring and reporting on progress. The UN must remain committed to full implementation and individual entities must invest required political commitment and resources to ensure implementation in the transformative manner intended. Gender mainstreaming will, hopefully, be a high priority on the agenda of the new entity, UNWOMEN, so that the UN can reclaim its global leadership role and provide vision and guidance in this area.

\section{LITERATURE}

- Hannan, Carolyn (2008): United Nations gender mainstreaming strategy: Achievements and challenges in Gender Studies and Policy Review Special Issue on Gender Mainstreaming. Seoul.

- UN (2006): United Nations system-wide policy on gender equality and the empowerment of women: Focusing on results and impacts. UN, New York.

. UN (2005): Review of the implementation of the Beijing Platform for Action and the outcome document of the special session of the General Assembly entitled "Women 2000: Gender equality, development and peace for the twenty-first century". UN, New York.

- UN (1997): ECOSOC Agreed Conclusions 1997/2. UN, New York. - UN (1996): Report of the Fourth World Conference on Women, Beijing, 4-15 September 1995. UN, New York.

Carolyn Hannan, PhD, Associate Professor Department of Social and Economic Geography University of Lund, Sweden 